\title{
https://doi.org/10.48009/1_iis_2006_83-87 \\ DEVELOPMENT OF PROJECT DOCUMENTATION: KEY INGREDIENT IN TEACHING SYSTEMS ANALYSIS AND DESIGN
}

\author{
Mohammad A. Rob, University of Houston-Clear Lake, rob@uhcl.edu
}

\begin{abstract}
Systems Analysis and Design (SAD) is a course commonly taught in almost all MIS programs. Most students do not understand the significance of this course until they enter the workforce. It is not always easy to make this course interesting to students due to its theoretical nature and it does not lend itself to hands-on activities that are readily encountered in courses such as programming or database; however, the course requires prior knowledge on these subject matters. In this paper, we present a project-based methodology of teaching systems analysis and design that focuses on the development of system documentations that keeps students engaged in key activities of the Systems Development Life Cycle.
\end{abstract}

Keywords: Systems Development Life Cycle, SDLC, Systems Analysis and Design, SAD, Teaching, Curriculum, Project-based Learning

\section{INTRODUCTION}

Teaching Systems Analysis and Design (SAD) through cases, projects, and role-playing received significant attention in the past decade. Many textbooks provide a running case problem at the end of each chapter to provide a business scenario and further clarification to the subject matters [2, 8]. Instructors have been using group projects and roleplaying in a variety of ways to engage students and convey necessary knowledge that a systems analyst should possess. For example, Sullivan [9] emphasized the project management aspect of software development projects through role-playing between instructor and students. Adams [1] stressed project management documentation while students acted as reviewers of documents and prototypes created by each other's groups. Kris [3] described teaching SAD through role-playing between instructor and students, while they acted as personnel of a software development company. Nance [5] used group projects to improve students' soft skills such as teamwork, group development, and project management. Kovacs and Rowell [4] focused on the development of an end-product such as a web-based project.
It should be clear from the above discussions that instructors have been trying to develop innovative ways to transfer many knowledge areas covered in a SAD course or that reflect the job description of a multi-tasking systems analyst. On the other hand, it is found that most of the instructors focused on a particular aspect of knowledge such as team building, project management, role-playing, deliverables, or end-product development. Research also shows that most instructors in the Systems Analysis and Design course focused on teaching "soft-skills" such as roleplaying, communication, and team management. However, recently there is a paradigm shift where instructors are moving towards teaching hard skills by incorporating real-life projects in classrooms.

In teaching the SAD course, we adapt a group-project methodology that requires students to perform all steps or activities prescribed in various phases of the SDLC and develop key documents at the end of each of the activities. By performing the prescribed activities and producing required outputs in a group environment, students go through the experience of a true systems analyst found in today's workforce.

\section{PROJECT-BASED LEARNING}

Project or Inquiry-Based Learning is an instructional method that uses complex, real-life projects to motivate learning and provide learning experiences; the projects are authentic, yet adhere to a curricular framework [6]. It allows teachers to create tasks, the complexity and openness of which mimic problems in the real world [7]. Projects that have depth, duration, and complexity will challenge students and motivate them towards construction of knowledge. Project-based learning provides a cross-collaborative learning environment in which students learn better through interaction with each other [5]. It provides improved understanding of subject matter, helps develop communication, planning and teamwork, and provides opportunities to take responsibility or charge. Teams outperform individuals acting alone or in a larger group, especially when performance requires multiple skills, judgments, and experiences [10].

Successful learning through a group project requires organization in key areas such as types of group 
project, selection of the project, and selection of project group. A group project may live only during a class period or it may be stretched over a semester. Teaching unrelated concepts of a course may be suitable in the former case, while teaching related concepts such as that in the SDLC is suitable for a semester-long project. A semester-long project may be a fictitious or published case problem or it can be a real-life problem. A realistic project that represents today's business environment and implements necessary activities of cross-functional areas of a business domain is suitable for a group project. There are various ways of selecting a project. It can be selected by the instructor or by the students, and all students may work on the same business problem or different problems. Multiple business problems can foster more knowledge and class participation than a single problem. There are many different ways a project team may be organized [10]. Depending on the type of the project selected, an entire class may act as a project team or a class can be divided into multiple groups.

\section{COURSE ORGANIZATION}

We design our course curriculum on the framework of the project-based learning in a collaborative environment. The course is organized to provide multiple areas of knowledge through lectures, group projects, group presentations, documentations, research papers, classroom writing, and discussion.

The main focus of this paper is the group project part of the course. While the students work on their group projects by implementing the activities of the SDLC, the instructor applies a project management style in planning, monitoring, and controlling overall students' activities in the course. The course plan is set through defining deadlines for specific course activities such as making of groups, scheduling group presentations, setting deadlines of research papers, and defining dates for tests and submission of final project binder containing all project documents. A copy of the current syllabus and other resources can be found on the course web site: (http://coursesite.isam.cl.uh.edu/rob/Course/SAD/SA D.htm).

At the beginning of each class period, the instructor goes through the lecture topic drawing students' past knowledge on the subject matter or making a parallel scenario experienced by most students in their daily lives. They are then asked to apply the knowledge in their own project through the development of necessary documentation. By the second or third week, project groups are formed and presentation schedules are completed and posted on the web site. Students are expected to develop each of the documentations that are covered in the previous lecture and be prepared for presentations. However, some adjustment to the presentation schedule occurs during the weeks of presentations. This is intentional and expected due to the reasons described below.

\section{The Group Project}

The purpose of the group project is to offer first-hand knowledge to each of the activities of the SDLC as well as to provide some experience with soft skills such as communication and team building. In the first few years of teaching, our focus was to go through the SDLC activities and develop a system prototype; however, in subsequent years emphasis was placed mainly on the planning, analysis and design phases of the SDLC. This is driven by three factors: (i) the nature of the course as well as all the coverage of all SAD textbooks, which mainly focus on the first three phases of the SDLC; (ii) the concept that a welldesigned system will produce a better product; and (iii) students already have experience of developing system prototypes through courses such as database or web development.

Our group project activities fit the model of team development as proposed by Wells [10], which suggests four stages of team development: forming, building, management, and assessment. Students are given the opportunity to select their own projects, and it is found to work successfully in our classroom, possibly due to the availability of a good mixture of working and mature students. Our purpose is that the students select a system of sufficient complexity and detail that challenge and enhance their systems development knowledge and skills.

Depending on the size of the class, a group consists of 2 - 3 students. When the class size was 40, a group consisted of three students, and in the current enrollment at the $50 \%$ level, the group size is 2 . As the majority of the group project activity is outside the classroom, it is found that for a larger group, the number of communication channel increases, and many times a group member fails to participate due to poor communication or schedule conflicts.

In order to make sure that the students go through the activities of the SDLC in a successful manner, we focus on several aspects of the course that are implemented through the group project. They are models or techniques covered in SDLC, presentations, tools, and documentations (see Fig. 1). 


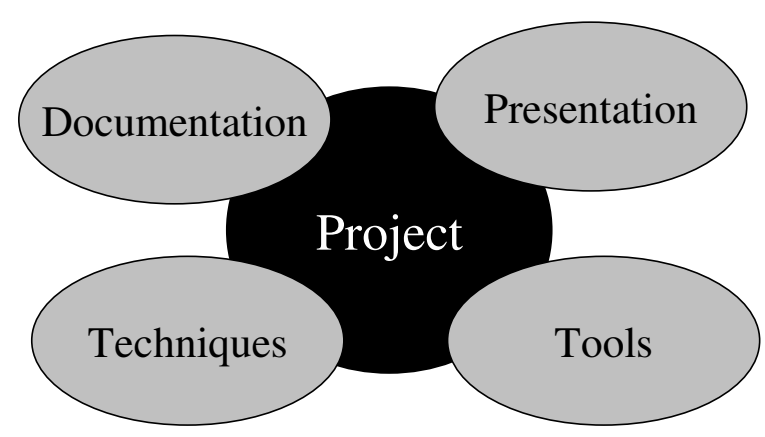

Figure 1: The Constituents of a Group Project

Models and Techniques: Students are expected to gain substantial knowledge on the models and techniques covered in the SDLC. These include system request, feasibility study, project plan, dataflow diagrams, data dictionary, entity-relationship diagram, program design, and user interface design. Students go through the activities of developing documentations and make presentations on key concepts to master these models and techniques.

Tools: In the workplace, an analyst is expected to use many different tools to complete project documentations and to communicate with all stakeholders. As such, students are required to use tools such as Microsoft Visio, Visible Analyst, Microsoft Project, and other Microsoft Office tools such as Word, PowerPoint and Access to develop system models, project plans, presentations, data dictionary, user interfaces, and system prototypes.

Presentation: Communication is one of the most important skills a systems analyst must have. A systems analyst has to interview customers to obtain systems requirements, develop all system-related documents, and present those to customers in both written and verbal manner. There are four presentations during the semester. They are focused on the key models or techniques covered in the SDLC such as system request, process models, data models, and program design. The presentations are scheduled only after the completion of the topic in the class, and they serve as milestones for the progress of the project activity. It is expected to have repetitions or rescheduling of some presentations, especially that of the process modeling. Groups learn from each other and they are required to modify their presentations until the expected knowledge is found to be acquired.

Documentation: The most important job of a systems analyst is to develop all system-related documents leading to the design specification for the to-be systems. A well-designed specification leads to the successful development of a system. Thus our main focus of the group project is to develop all documentation by the students as they go through each of the activities of SDLC in a waterfall methodology. Dennis et. al. [2] provide a listing of the activities as well as the documents to be produced at the completion of each of the activities. Figure 2 shows a similar listing from the course syllabus that the students are required to develop in various phases of the SDLC. Through the development of documentation, students also develop mastery in their written communication skill.

Starting Spring 2006, these documents were organized and posted in a web site by each group (http://coursesite.isam.cl.uh.edu/rob/Course/SAD/Stu dentProjects/Spring2006/SADProjectSpring2006.htm ). Figure 3 shows an example home page of a group project.

\section{DISCUSSION}

In our MIS curriculum, teaching SAD through group projects is found to be more suitable to graduate students than undergraduates. Undergraduates seem to work better with a defined case problem found at the end of each chapter of a SAD text [8] as opposed to an open-ended group project. Maturity and motivation play important roles in the success of the group project at the graduate level. These students are also found to have a better understanding of required knowledge of database, programming and networking. Also, the documentations created by graduate students are found to be superior than that of the undergraduates. Although we use a web site for all teaching resources, until recently the documentations have been submitted as a hard copy in a binder at the end of the semester. There seems to be a drawback in this method. Although students are expected to complete all documents as each SDLC activities are discussed in class, in reality it is found that many students are not up-to-date with the documentation. Having a new requirement that all documents must be posted on the web site as each activity is completed will solve some of this problem. 


\section{Table of Contents}

Project Summary

Systems Planning

- Identify problems and define proposed solutions (System Request)

- Feasibility Analysis

- Cost-benefit analysis, etc.

- Project Plan

- Size Estimation

- Work Breakdown Structure

- Work Plan (Gantt chart/Pert diagram)

- Staffing Plan

- Standards

- $\quad$ Risk Assessment

Systems Analysis

- Requirements Gathering Documentation

- Data Flow diagram

- Context-level diagram

- 0 -level diagram, etc.

- Next-level diagrams

- Data dictionary

- Data flow with data structure

- Data storage with data structure

- Data input and data structure

- Data output and data structure

- Data element description

- Process description

Systems Design

- Database design (E-R diagram)

- Document and design input screens

- Document and design output reports/screen

- Document and design menu system

- Program design

- Program test design

- System architecture

\section{Systems Implementation}

- Database development (tables and queries)

- Program codes

- User interface (screen capture of forms and reports)

- Program testing results

Systems Support (if any for the future)

\section{Appendix}

Figure 2. List of Documents to be Produced for the Group Project 


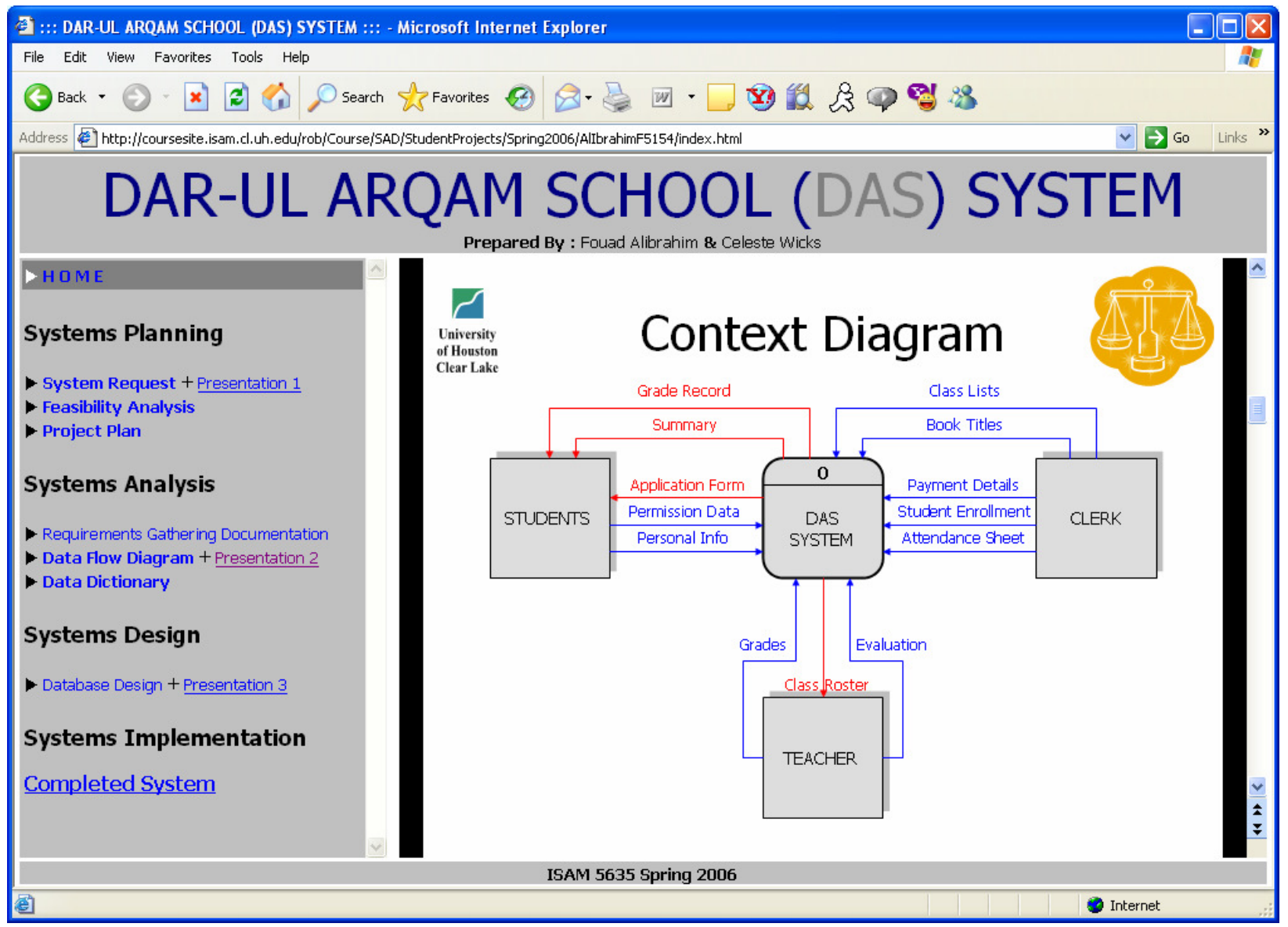

Figure 3. Sample Home Page of a Web Site Created by Students to Store Online Documents for a Group Project

\section{REFERENCES}

1. Adams, E. J. (1993). A Project-Intensive Software Design Course, ACM SIGCSE Bulletin, Proceedings of the twenty-fourth SIGCSE technical symposium on Computer Science Education SIGCSE '93, 25(1), 112-116.

2. Dennis, A., Wixom, B. H., \& Roth, R. M. (2006), Systems Analysis and Design, John Wiley and Sons.

3. Kirs, P. J. (July/August, 1994). A Role-Playing Approach to the Instruction of Information Systems Analysis and Design Courses, Journal of Education for Business, 69(6), 317-325.

4. Kovacs, P. \& Rowell, D. (January 2001). The Merging of Systems Analysis and Design Principles with Web Site Development: One University's Experience, The Journal, 28(6), 6064.

5. Nance, W. D. (1998). Experiences with an Innovative Approach for Improving Information Systems Students' Teamwork and Project
Management Capabilities, ACM Proceedings of the 1998 Conference on Computer Personnel Research, 145 - 151 .

6. Project Based Learning; http://www.iearncanada.org/guideontheside.html, accessed 2/27/06.

7. Project Based Learning; http://pblchecklist. 4teachers.org/, accessed 2/27/06.

8. Shelly, G. B., Cashman, T. J., \& Rosenblatt, H. J., (2006). Systems Analysis and Design, Thomson Course Technology: Boston, MA.

9. Sullivan, S. L. (1993). A Software Project Management Course Role-Play Team-Project Approach Emphasizing Written and Oral Communication Skills, Proceedings of the Twenty-Fourth SIGCSE Technical Symposium on Computer Science Education, 283 - 287.

10. Wells, C. E. (2002). Teaching Teamwork in Information Systems," Challenges of Information Technology Education in the 21st Century, Hershey, PA: Ideal Group Publishing, $1-24$. 